\title{
The Estimation Modeling of Abutment Volume with Variations of Bridge Span, Abutment Height, and Seismic Zone
}

\author{
Dicky Rahadian Mahendra*, Andreas Triwiyono \\ Department of Civil and Environmental Engineering, Universitas Gadjah Mada, Yogyakarta, INDONESIA \\ Jalan Grafika No 2 Yogyakarta Engineering, Universitas Gadjah Mada, Yogyakarta, INDONESIA \\ *Corresponding authors: dicky.rahadian.m@mail.ugm.ac.id
}

SUBMITTED 7 April 2020 REVISED 5 May 2020 ACCEPTED 4 September 2020

\begin{abstract}
The initial cost of a bridge project determined using an estimation model depends on the dimensions, types, and materials but only a few studies have included bridge location as a determinant variable. The inclusion of the location is, however, important due to the different seismic accelerations and seismic load analysis attached to it. Therefore, this study aimed to create a model to calculate the quantity of materials needed for the construction of abutment in different locations with a PCI-Girder superstructure. Moreover, the data used for the quantity estimation model was derived from the abutment design results and those associated with concrete and reinforcing steel quantities were based on the variations of the bridge span at $20 \mathrm{~m}, 25 \mathrm{~m}, 30 \mathrm{~m}, 35 \mathrm{~m}$, and $40 \mathrm{~m}$, abutment height at $4 \mathrm{~m}, 6 \mathrm{~m}$, and $8 \mathrm{~m}$, and seismic zone 1, 2, 3, and 4 . Meanwhile, the volume estimation models were obtained through multiple linear regression analysis. The results showed a very strong correlation between the span of the bridge and the height of abutment with the dependent variables while the seismic zone was observed to have a strong correlation with the dependent variables but was unable to meet the linear regression assumptions. Therefore, the statistical analysis was conducted separately for each seismic zone and the data for abutment height was transformed from $H$ into $H^{2}$. This study developed 8 models with $R^{2}$ values ranging between $0.983-0.997$ and this means they were adequately designed to estimate abutment volumes with a PCl-Girder superstructure.
\end{abstract}

KEYWORDS Abutment; Volume Estimation; I-Girder; Seismic Zone; Linear Regression.

(C) The Author(s) 2021. This article is distributed under a Creative Commons Attribution-ShareAlike 4.0 International license

\section{INTRODUCTION}

\subsection{Background}

The accuracy of initial cost estimation is necessary to ensure a successful project budgeting and this depends on the available information and data related to the project (Oh, et al., 2013) while the inaccuracies in the estimation are mostly associated with the incompleteness of information and data with the most frequent discrepancy reported to be occurring in works volume. It is, therefore, possible to have more accuracy by increasing the precision during the calculation of works volume required for bridge construction but the process is usually through the use of the data from previous projects but the estimation is expected to be more accurate when the data is adjusted to the characteristics and type of the new bridge. Moreover, it has been reported that it is very difficult to have a precise initial cost estimate due to the availability of limited information on a new project (Fragkakis, et al., 2015). Some of the factors usually used as determinants or independent variables include dimensions such as span, width, and height as well as the type and materials of the bridge such as concrete, steel, timber, and composite. Meanwhile, only a few studies have included bridge location as a determinant variable.

The latest Indonesian standard for Bridge Design Specification for Earthquake Load is SNI 2833:2016 and it divides the seismic zone into four categories which are zones $1,2,3$, and 4 based on the soil surface acceleration at 1 second period $\left(S_{D 1}\right)$. It was discovered that different locations have different accelerations based on geological conditions and Indonesian seismic records and this means they also have varying seismic zones and seismic load analysis. This variation has the ability to cause changes in the volume needed for bridge construction, therefore, this study focused on determining the initial cost estimation using the seismic zone as a predictor variable. 
Several studies have been conducted on cost estimation for construction with the early cost estimating models for road construction projects reported to be developed using multiple linear regression by Mahamid (2011) while those related to socket foundation, bore pile foundation, and footplate foundation using linear regression were conducted by Fragkakis, et al. (2011). Moreover, a model was also designed by Kim (2011) for the approximate cost estimation of a railway bridge project in the planning phase using CBR (Case-Based Reasoning) method, and the model associated with abutment, pier, and foundation based on standard quantity was studied by $\mathrm{Oh}$, et al. (2013). Moreover, a preliminary engineering cost estimation model was developed for bridge projects by Hollar, et al. (2013) with data from completed projects using linear regression while the best estimating techniques for building constructions were determined by Kim, et al. (2013). Another model was designed using linear regression by Fragkakis, et al. (2015) to estimate the cost required for culverts' material quantities while a parametric approach was implemented to enhance the earlier estimation of the cost needed to construct a better pavement by Swei et al. (2017). Furthermore, an early bill-of-quantities (BoQ) estimation was developed for concrete road bridges by Dimitriou, et al. (2018) using Feed-Forward Artificial Neural Networks (FFANNs) while project location was applied as a determinant factor in estimating cost by Kim (2011) but was observed to have a little or no impact in the CBR method through the calculation of attribute weight using Generic Algorithm and was later removed. Some studies also used seismic zone as a cost estimate predictor but most of the data were observed to have a similar zone and this led to its exclusion (Fragkakis, et al., 2011; Fragkakis, et al., 2015) due to the fact that they were mostly based on the previous project. A similar study was conducted by Alhusni, et al. (2019) with a model based on engineering design results to estimate the cost of constructing a bridge from the design stage.
A bridge cost estimation model was developed by Alhusni, et al. (2019) to calculate the abutment and well foundation volume needed for construction based on the volume from the engineering design using regression analysis and predictor variables of bridge span and abutment height. The study was, however, conducted based on an outdated standard (SNI 2833:2008) instead of the latest SNI 2833:2016 and also focused on one location, thereby, making the model applicable only in locations with similar characteristics. Therefore, this current research was conducted based on SNI 2833:2016 using the seismic zone as a predictor variable to represent different locations of the bridge project, the load analysis was calculated in line with SNI 1725:2016 which is the Indonesian standard for bridge loading, the reinforced concrete structure analysis was established on RSNI-T-2004 which is the Indonesian standard for the concrete design for bridge construction, and the resistance factor was in reference to the AASHTO LRFD Bridge Design Specification 2012 in accordance with SNI 1725:2016.

The purpose of this study was to create a model to calculate the quantity of materials needed for abutment construction in several locations. It is important to note that the model extends beyond the case study locations by being applicable in other areas in Indonesia with similar characteristics and abutment design. It is possible to adequately formulate the initial cost estimate for abutment by applying a proper material unit price to the estimated volume to ensure quickness and flexibility. Moreover, different values of the bridge span, abutment height, and seismic zone were applied as predictor variables while multiple regression analysis was used to develop the models. It is important to note that the models were simple and only require minimum information at the early stage of the bridge project. Furthermore, the research also described the influence of the variations of the predictor variables on the abutment volumes, and the results are expected to suggest a point of concern for others to develop a better estimation model to determine 
the cost of constructing a bridge at the early stage of the project.

\section{METHODS}

This study was conducted in two steps with the first focused on the development of a database consisting of the total quantity of concrete and reinforcing steel needed to complete a total of 2 bridge abutments construction using different variations of the bridge span, abutment height, and seismic zone for statistics analysis. These quantities were calculated based on each design result and a total of 60 designs were produced with the database displayed in graphics to determine the direction and correlation between the variables as observed in the use of independent variable as $X$ (or axis) and a dependent variable as $Y$ (or ordinate). The second step involved the statistical analysis conducted to determine the correlation between the variables, linear regression assumption, regression linear analysis, and goodness of fit using the SPSS software.

\subsection{Study Case and Limitations}

Several cases used in this study were determined to fulfill the structural analysis requirement and some of the materials include concrete with $f_{c}$ at $25 \mathrm{MPa}$ and reinforcing steel with $f_{\mathrm{y}}$ at $390 \mathrm{MPa}$ and the soil parameter was assumed to be noncohesive at $c=0 \mathrm{kPa}$ with weight volume, $\lambda=18$ $\mathrm{kN} / \mathrm{m}^{3}$ and internal friction angle, $\phi=35^{\circ}$ while the soil below the foundation was assumed to be hard. Moreover, the seismic zone considered several locations in Indonesia as presented in Table 1 while the elastomer bearing pad was designed based on the product specifications from PT. Basis Pancakarya (2019). Meanwhile, The detailed limitations of this study such as the bridge type and dimensions are explained further in Sections 2.2 and 2.3.

Table 1. Bridge locations

\begin{tabular}{lllll}
\hline Seismic Zone & Location & $\mathrm{PGA}^{*}$ & $\mathrm{Ss}^{*}$ & $\mathrm{~S} 1^{*}$ \\
\hline Zone 1 & Makassar & 0.10 & 0.20 & 0.08 \\
Zone 2 & Palembang & 0.15 & 0.25 & 0.15 \\
Zone 3 & Bandar & 0.30 & 0.60 & 0.30 \\
Zone 4 & Lampung & & & \\
& Yogyakarta & 0.50 & 1.20 & 0.60 \\
\hline
\end{tabular}

*Unit in gravity $\left(\mathrm{g}=9.81 \mathrm{~m} / \mathrm{s}^{2}\right)$

\subsection{Superstructure Dimensions}

The previous superstructure design in an earlier study focused only on the determination of the bearing reaction (Alhusni, et al., 2019) and a similar method was applied in this research but the I-Girder used comprehensively explained the bridge span. Moreover, the superstructure was designed based on the product specification of precast post-tension concrete PCI-Girder produced by PT. Wijaya Karya (WIKA BETON) (2019) in Indonesia and the dimensions complied with the A-class bridge superstructure in accordance with the requirements of Direktorat Jendral Bina Marga (Department of Highway in Indonesia). It has a $7 \mathrm{~m}$ width roadway and $1 \mathrm{~m}$ width sidewalk at both sides to make a total of 9 $m$ as shown in the typical cross-section of Figure 1 .

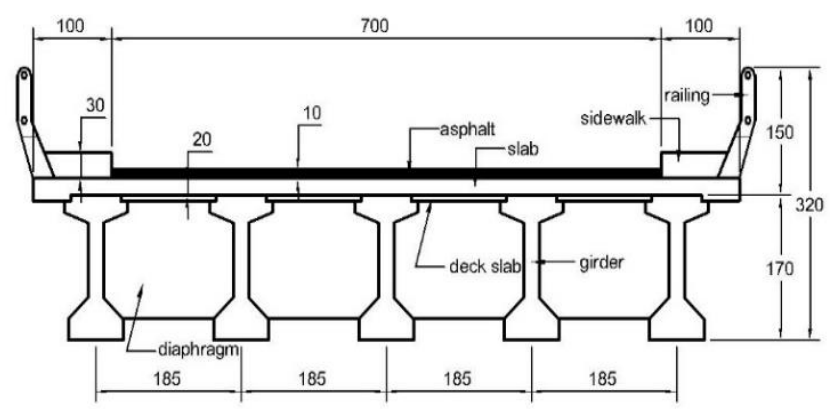

Figure 1. A-class bridge cross-section

\subsection{Abutment Modeling and Analysis}

A full-height cantilever abutment type with a bored pile foundation was used and the parts are shown in Figure 2 with the length discovered to be equal to the $9 \mathrm{~m}$ superstructure width while the back wall height was determined based on the total height of I-Girder and elastomer bearing. Moreover, the I-Girder used was based on the bridge span and this means $20 \mathrm{~m}$ spans used PCI H-125 which is $125 \mathrm{~cm}$ high, $25 \mathrm{~m}$ span used PCI H-160 which is $160 \mathrm{~cm}$ high, $30 \mathrm{~m}$ and $35 \mathrm{~m}$ spans used PCI H-170 which is $170 \mathrm{~cm}$ high, and $40 \mathrm{~m}$ spans used PCI $\mathrm{H}-210$ which is $210 \mathrm{~cm}$ high. The elastomer bearing has $10-12 \mathrm{~cm}$ height while the back wall consists of two parts which are the top with $0.30 \mathrm{~m}$ width and bottom with $0.50 \mathrm{~m}$. The excess $0.20 \mathrm{~m}$ was, however, provided for approach slab bearing. 
The breast wall width was determined using the bearing placement minimum length which was designed to accommodate elastomer length and provide sufficient space for it to deform. The eccentricity of the breast wall towards the center base of footing was allowed to have a maximum of $0.20 \mathrm{~m}$. Meanwhile, he footing has $0.60 \mathrm{~m}$ height at the free end while the height at the fixed end was determined based on the different abutment heights for $4 \mathrm{~m}, 6 \mathrm{~m}$, and $8 \mathrm{~m}$ which was $1.20 \mathrm{~m}, 1.60 \mathrm{~m}$, and $2.00 \mathrm{~m}$ respectively. The footing length was decided using the pile reaction to avoid any negative or upward reaction on the bored pile and the amount of pile used was based on the variation of the abutment height with $2 \times 5,3 \times 5$, and $4 \times 5$ recorded for 4 $\mathrm{m}, 6 \mathrm{~m}$, and $8 \mathrm{~m}$ respectively. The bored pile was, however, analyzed only to obtain the reaction on each pile.

The wing wall height was observed to be equal to the overall height of the abutment but has a width of $0.60 \mathrm{~m}$. Its length was the same as the value for the back footing with an additional 0.80 $\mathrm{m}$ while the corbel dimensions were found to be the same for all variations with 0.45 width, 0.50 $\mathrm{m}$ height at the free end, and $0.95 \mathrm{~m}$ height at the fixed end.

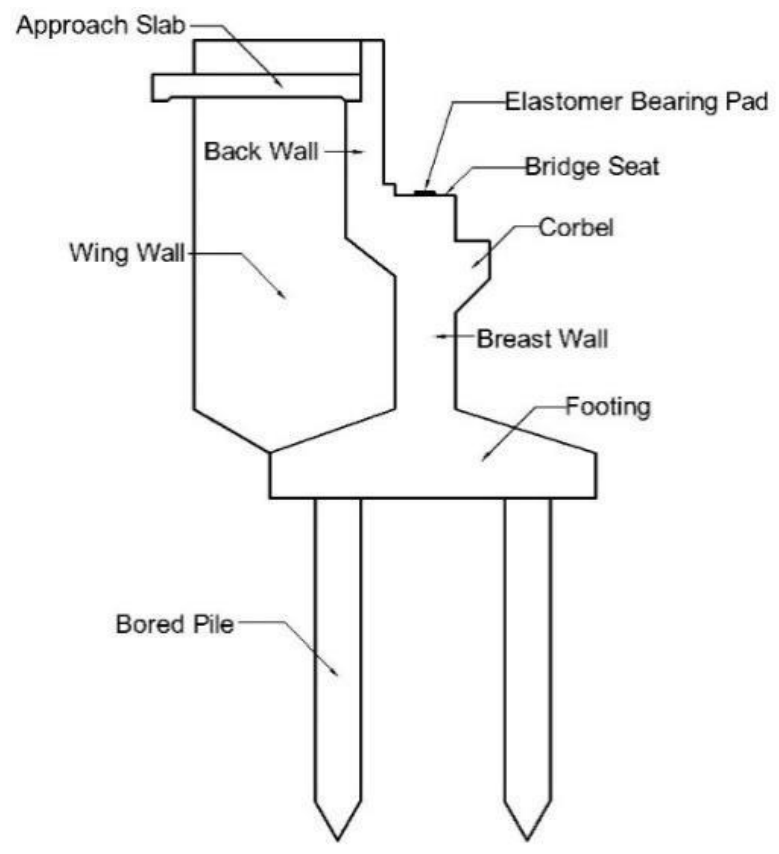

Figure 2. Abutment parts
The abutment was analyzed by calculating the load working on it based on the dimension previously determined while the loads from the superstructure were calculated as static loads and transferred to the abutment through bearing pads. Moreover, the loads working directly on the substructure were considered as static loads and the abutment cross-section capacity on each part was determined based on the combined load according to the SNI 1725:2016. Meanwhile, the satisfied design result was achieved when all the parts of the abutment cross-section have enough capacity to support all the combined loads.

A single-mode static earthquake analysis was used in this study and it was selected because the bridge only has one span and the superstructure was considered to be a simple beam while the substructure was a cantilever wall with the support on the bottom of the footing. This modeling has an SDOF (single degree of freedom) system and the fundamental period of each superstructure and substructure was calculated and integrated into the design response spectrum to obtain the seismic acceleration coefficient $\left(C_{s m}\right)$. Moreover, the seismic load was determined by multiplying the self-weight of the structure with $C_{s m}$, and the result was further applied in the center of gravity on each superstructure and substructure separately as a static horizontal load.

\subsection{Estimation Modeling}

The estimation model was developed using multiple linear regression analysis and was used to determine the required variables. The dependent variables were based on the values to be determined such as concrete volume $\left(V_{c}\right)$ and reinforcing steel weight $\left(V_{s}\right)$ while the independent variables were those with the ability to predict the value of the dependent ones and they include bridge span (L), abutment height $(\mathrm{H})$, and the seismic zone (Alhusni, et al., 2019) as indicated in Figure 3. Meanwhile, the seismic zone has ordinal or categorical types of data while bridge span and abutment height have ratio or numeric types. 


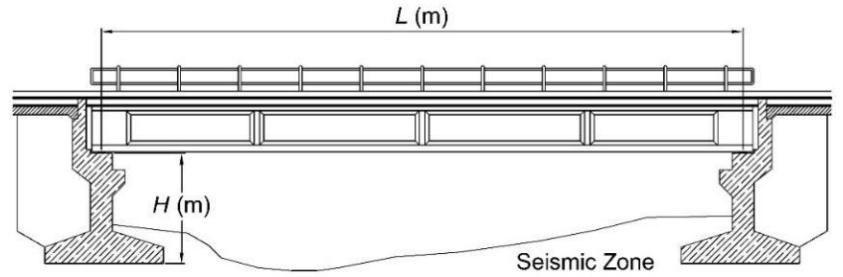

Figure 3. Longitudinal bridge cross-section

Linear regression has underlying assumptions and those considered in this study include linearity, normality, multicollinearity, and homoscedasticity. Any breach of these assumptions has the ability to cause the inefficiency of the regression model but this does not mean the model would be unable to be applied even though its accuracy has been reduced (Williams, et al., 2013). Some of the ways to ensure the assumptions were satisfied to include data transformation, the addition of more data, separation of the analyses, and several others. Meanwhile, the multiple linear regression equation is shown in Equation (1).

$Y=\beta_{0}+\beta_{1} X_{1}+\beta_{2} X_{2}+\cdots+\beta_{i} X_{i}$

Where, $Y, X_{i}$, and $\beta_{i}$ refers to the dependent variable, independent variable, and regression coefficient respectively while $\beta_{0}$ is constant.

\section{RESULTS}

The correlation between bridge span $(L)$ and concrete volume $\left(V_{c}\right)$ for each seismic zone of 1 , 2, 3, and 4 is shown in Figure 4, Figure 5, Figure 6 , and Figure 7, respectively and three curves are presented in each graph with each representing an abutment height $(H)$. All the graphs showed a positive and linear correlation and this is due to the use of higher I-Girder because of the greater bridge span, thereby, causing a higher bearing reaction at the support and dimension of the bearing pad which later increased the width of the bearing. This caused an increment in the breast wall width and back wall height. Moreover, a positive and linear correlation was also observed between abutment height $(H)$ and concrete volume $\left(V_{c}\right)$ too as indicated by the difference in the $V_{c}$ values for each $H$ but this did not cause any extreme change.
The curves at 25, 30, and $35 \mathrm{~m}$ spans showed the $V_{c}$ is almost constant due to the relatively small change in the PCI-Girder cross-section at these spans compared to 20 and $40 \mathrm{~m}$ and this further changed the abutment cross-section slightly, thereby, leading to the small variations in the concrete volume.

The correlation between $L$ and $V_{C}$ for seismic zone 1

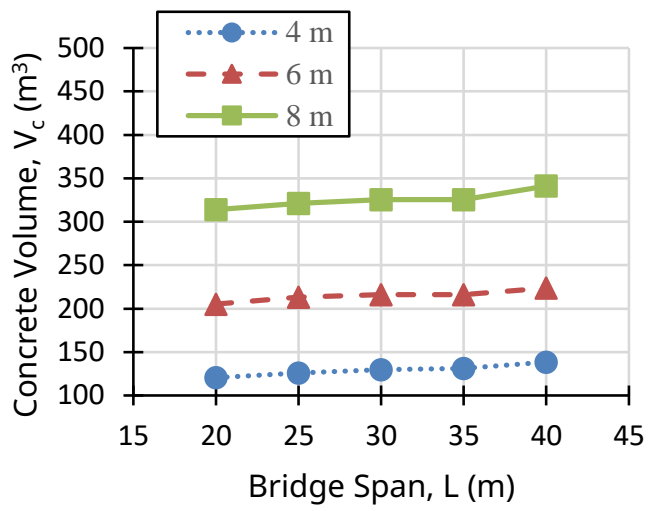

Figure 4. The correlation between $L$ and $V_{C}$ for seismic zone 1

The correlation between $L$ and $V_{C}$ for seismic zone 1

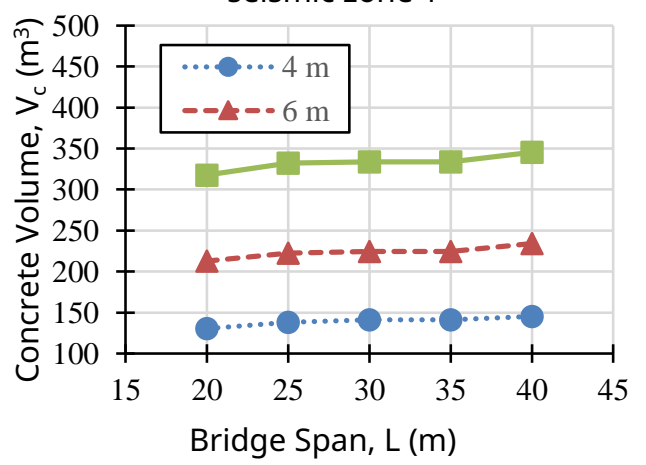

Figure 5. The correlation between $L$ and $V_{C}$ for seismic zone 2

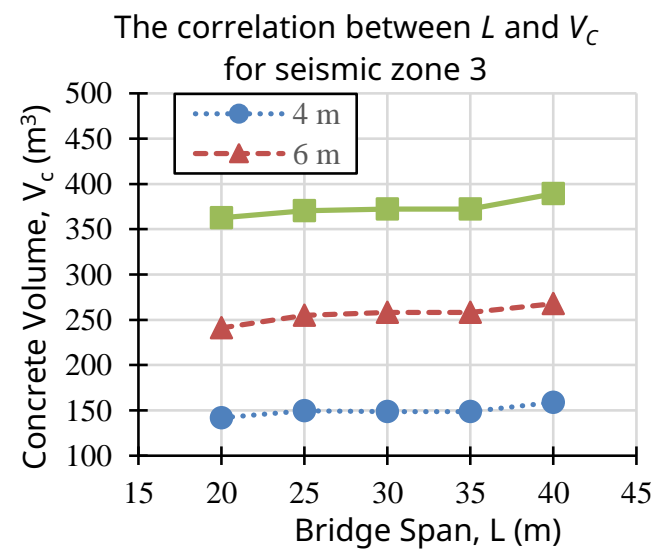

Figure 6 . The correlation between $L$ and $V_{C}$ for seismic zone 3 
The correlation between $L$ and $V_{C}$ for seismic zone 4

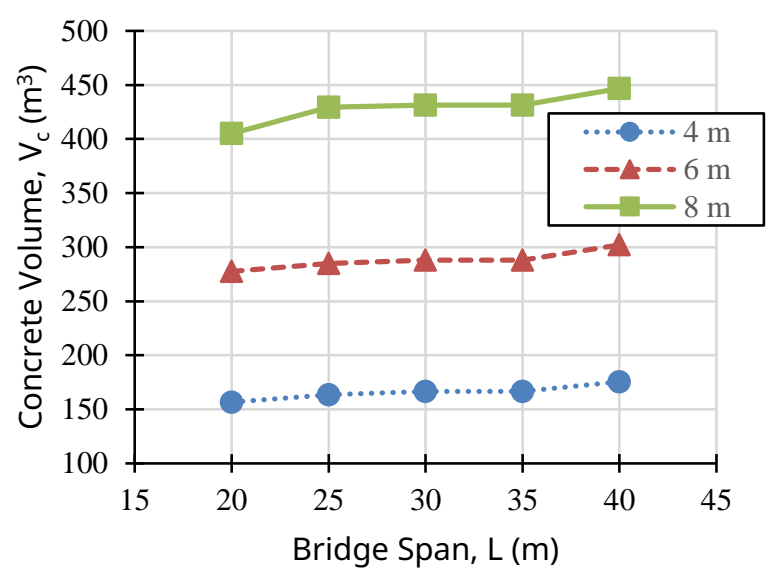

Figure 7. The correlation between $L$ and $V_{C}$ for seismic zone 4

The correlation between bridge span $(L)$ and reinforcing steel weight $\left(V_{s}\right)$ for each seismic zone of 1, 2, 3, and 4 is shown in Figure 8, Figure 9, Figure 10, and Figure 11 respectively and a positive and linear correlation is indicated in all the graphs. A higher bridge span was observed to have caused an increase in the abutment bearing load, a higher cross-section capacity needed on several abutment parts, and an increment in the volume of reinforcing steel. Moreover, a positive and non-linear correlation was found between abutment height $(H)$ and reinforcing steel weight $\left(V_{s}\right)$ and the difference was observed to have displayed an extreme change which becomes higher as the seismic zone increased. It was also discovered that the increase in $H$ led to the rise of the moments works on the footing and the length of the footing experienced an increment to withstand the abutment stability. Meanwhile, the weight change of the reinforcing steel at 20 and $40 \mathrm{~m}$ spans was relatively high compared to the other spans due to the relatively small change in the PCI-Girder cross-section at 25, 30, and $35 \mathrm{~m}$ spans in comparison with 20 and $40 \mathrm{~m}$.

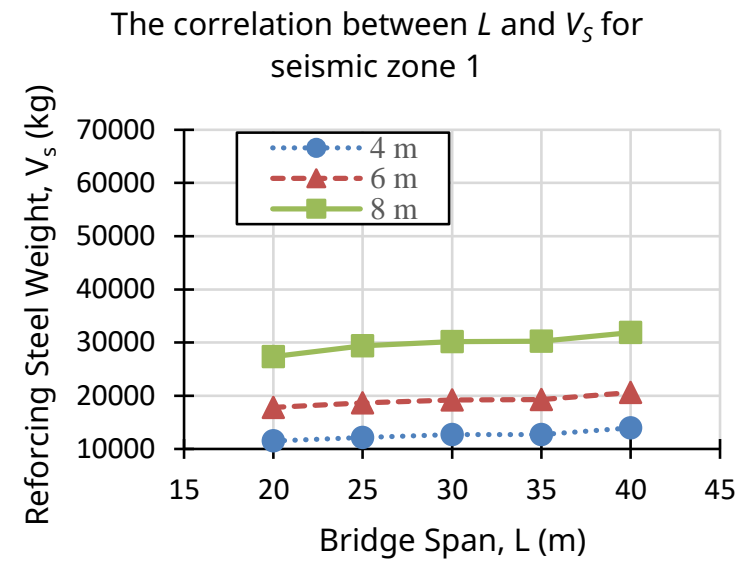

Figure 8. The correlation between $L$ and $V_{S}$ for seismic zone 1

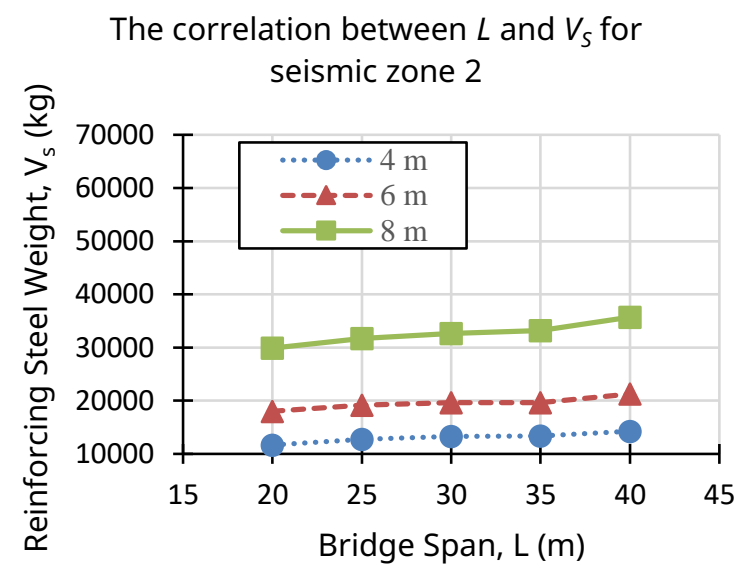

Figure 9. The correlation between $L$ and $V_{s}$ for seismic zone 2

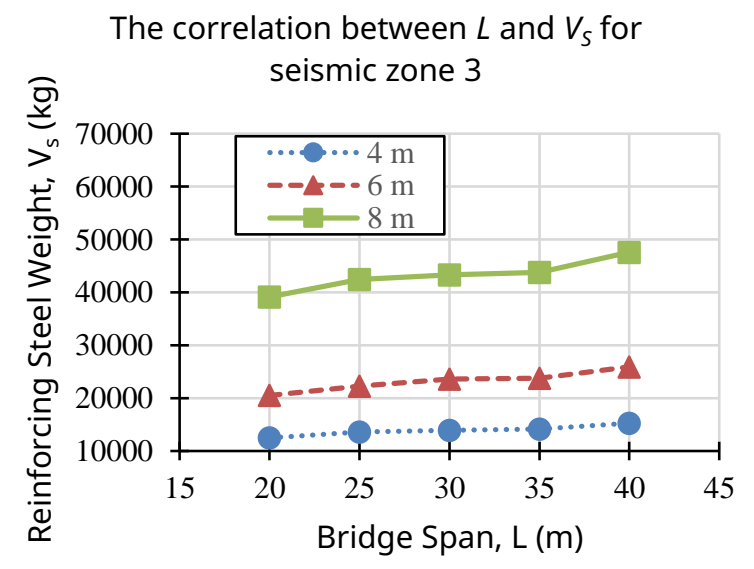

Figure 10. The correlation between $L$ and $V_{S}$ for seismic zone 3 


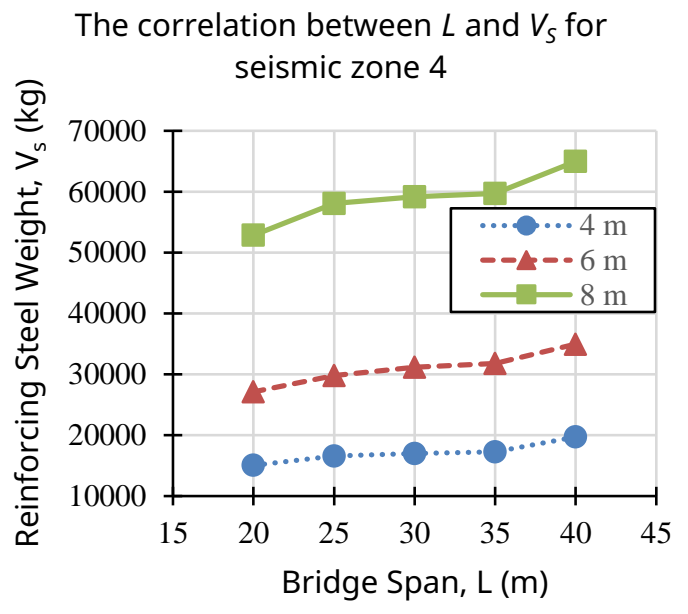

Figure 11. The correlation between $L$ and $V_{S}$ for seismic zone 4

The correlation between seismic zone and concrete volume $\left(V_{C}\right)$ is presented in Figure 12, Figure 13, and Figure 14, and 5 curves are observed in each graph to be representing each of the bridge spans $(L)$. A positive correlation which tends to be linear was discovered in these graphs and the increase in the seismic zone was found to be followed by an increment in the seismic acceleration, horizontal load, and bending moment in the bottom support, footing length, and concrete volume. Meanwhile, the changes in the concrete volume became higher as the abutment height increased.

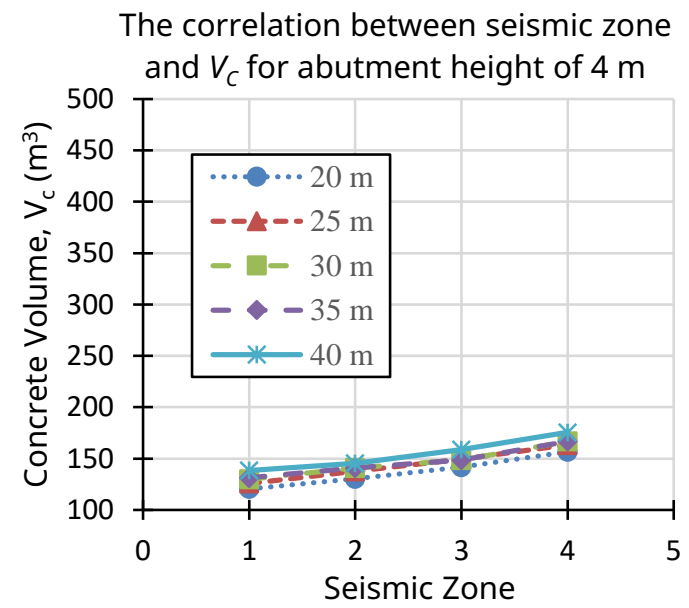

Figure 12. The correlation between seismic zone and $V_{C}$ for abutment height of $4 \mathrm{~m}$
The correlation between seismic zone and $V_{C}$ for abutment height of $6 \mathrm{~m}$

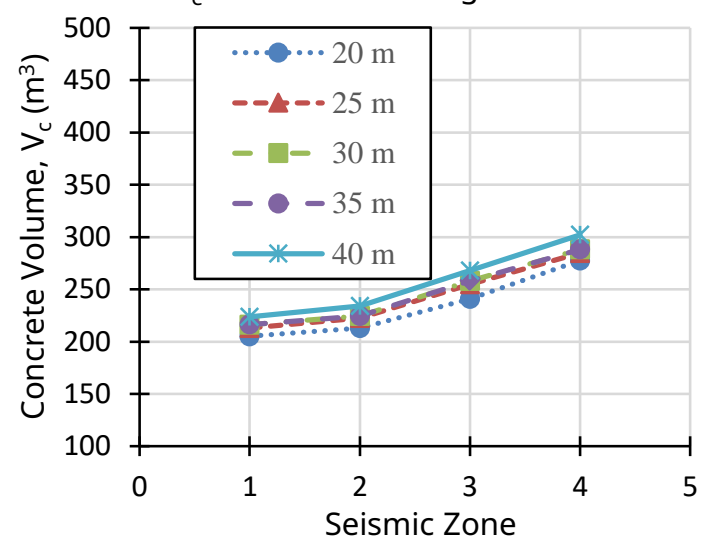

Figure 13. The correlation between seismic zone and $V_{C}$ for abutment height of $6 \mathrm{~m}$

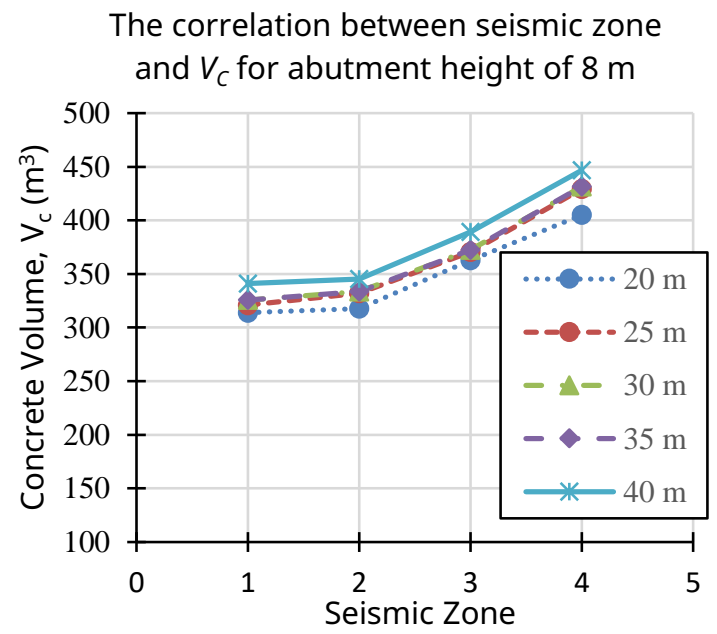

Figure 14. The correlation between seismic zone and $V_{C}$ for abutment height of $8 \mathrm{~m}$

The correlation between seismic zone and reinforcing steel weight $\left(V_{S}\right)$ is presented in Figure 15, Figure 16, and Figure 17 and the curves were observed to have a positive and non-linear correlation. An increase in the seismic zone was found to have caused a higher seismic acceleration and seismic forces on the abutment. Moreover, the non-linear correlation was discovered to be due to the non-linearity increase of the seismic acceleration as shown in Table 1 while the change in the reinforcing steel weight was recorded to have become higher as the abutment height increased. 


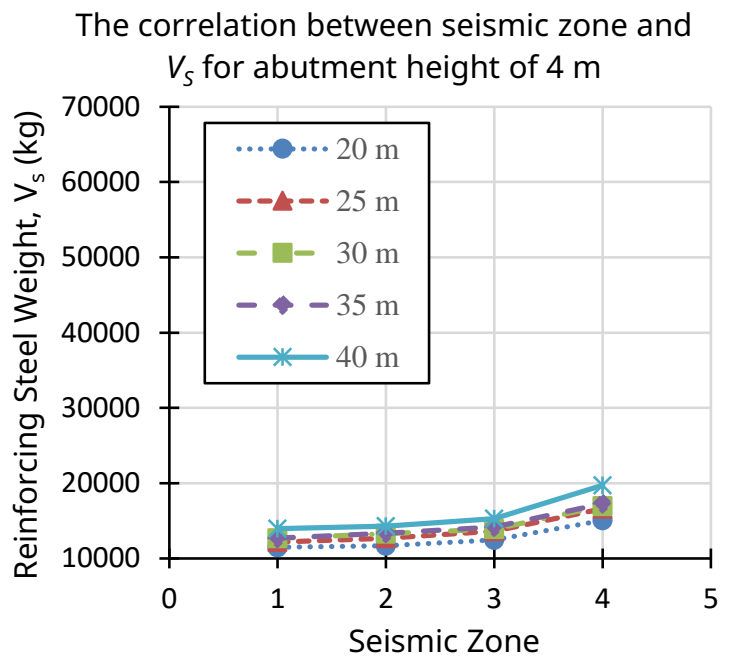

Figure 15. The correlation between seismic zone and $V_{s}$ for abutment height of $4 \mathrm{~m}$

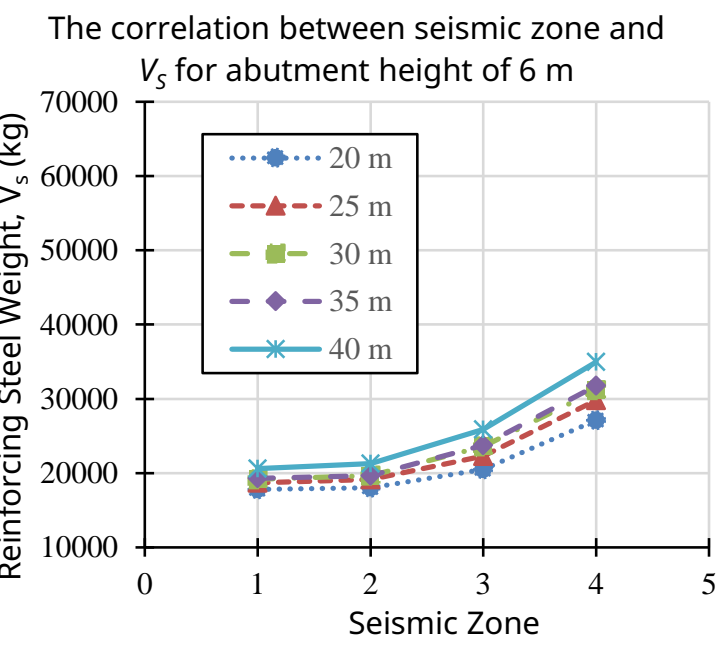

Figure 16. The correlation between seismic zone and $V_{S}$ for abutment height of $6 \mathrm{~m}$

The correlation between seismic zone and $v_{s}$ for abutment height of $8 \mathrm{~m}$

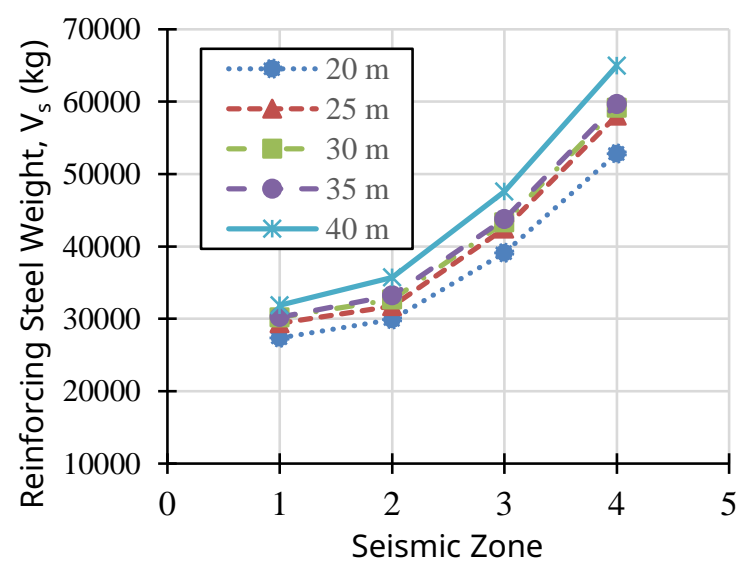

Figure 17. The correlation between seismic zone and $V_{S}$ for abutment height of $8 \mathrm{~m}$

\section{DISCUSSION}

The seismic zone which was an independent variable was observed not to meet several linear regression assumptions, therefore, the statistical analysis was conducted separately for each seismic zone.

\subsection{Linearity Test}

The linearity test was conducted graphically based on the data from the design result and linear correlation was established between $L$ and $V_{C}, L$ and $V_{S}$ as well as $H$ and $V_{C}$ while $H$ and $V_{S}$ had non-linear correlation. Therefore, the $H$ data was transformed into $H^{2}$ to obtain a better and more linear correlation.

\subsection{Normality Test}

The normality test was conducted on the residuals from multiple linear regression even though it was not required (Williams, et al., 2013) but the small samples in this study were the main reason for the test. Kolmogorov-Smirnov test was used and the results presented in Table 2 showed all the residuals were normally distributed with the asymptotic significance values greater than 0.05 , therefore, the normality assumption for the linear regression was accurate.

Table 2. Normality Test Result

\begin{tabular}{lll}
\hline $\begin{array}{l}\text { Dependent } \\
\text { Variable }\end{array}$ & Seismic Zone & $\begin{array}{l}\text { Asymptotic } \\
\text { Significance }\end{array}$ \\
\hline \multirow{4}{*}{$V_{c}$} & Zone 1 & 0.119 \\
& Zone 2 & 0.200 \\
& Zone 3 & 0.200 \\
& Zone 4 & 0.200 \\
$V_{s}$ & Zone 1 & 0.200 \\
& Zone 2 & 0.200 \\
& Zone 3 & 0.200 \\
\hline
\end{tabular}

4.3 Multicollinearity Test

The multicollinearity test was aimed to determine the existence of any correlation between the independent variables. Meanwhile, a good regression model is not expected to have any, and even though this is not considered a significant problem for prediction purpose, a 
perfect correlation of two or more predictor variable has the ability to cause the failure of the linear regression analysis (Williams, et al., 2013). Moreover, the determination of the predictor variable values led to the production of Tolerance and VIF (variance inflation factor) value of 1.00 and this means there was no multicollinearity problem in the data.

\subsection{Homoscedasticity Test}

The homoscedasticity test was conducted to check for the existence of any difference in the variance between residuals and predictor variables. A good regression model is, however, not expected to have any violation of homoscedasticity which is known as heteroscedasticity (Williams, et al., 2013). The study used the Glejser test and the results displayed in Table 3 showed the significance for each dependent variable to be greater than 0.05 and this indicates there was no heteroscedasticity problem.

\subsection{Correlation Analysis}

Multiple correlations were analyzed to determine the level of correlation between the dependent and independent variables and the results are displayed in
Table 4 and Table 5. It is, however, important to note that a Coefficient of $0.600-0.799$ is strong while $0.800-1.000$ is very strong (Sugiyono, 2019). Meanwhile, a partial correlation analysis was conducted between the seismic zone and abutment volumes ( $V_{C}$ and $V_{S}$ ) with $L$ and $H$ used as constant variables, and the results are presented in Table 6.

Table 3. Heteroscedasticity Test Result

\begin{tabular}{|c|c|c|c|}
\hline $\begin{array}{l}\text { Seismic } \\
\text { Zone }\end{array}$ & $\begin{array}{l}\text { Dependent } \\
\text { Variable }\end{array}$ & $\begin{array}{l}\text { Independent } \\
\text { Variable }\end{array}$ & Significance \\
\hline \multirow{4}{*}{ Zone 1} & \multirow{2}{*}{$V_{C}$} & $L$ & 0.465 \\
\hline & & $H$ & 0.949 \\
\hline & \multirow[b]{2}{*}{$V_{S}$} & $L$ & 0.777 \\
\hline & & $H^{2}$ & 0.330 \\
\hline \multirow{4}{*}{ Zone 2} & \multirow{2}{*}{$V_{C}$} & $L$ & 0.718 \\
\hline & & $H$ & 0.755 \\
\hline & \multirow{2}{*}{$V_{S}$} & $L$ & 0.752 \\
\hline & & $H^{2}$ & 0.981 \\
\hline \multirow{4}{*}{ Zone 3} & \multirow{2}{*}{$V_{C}$} & $L$ & 0.942 \\
\hline & & $H$ & 0.976 \\
\hline & \multirow{2}{*}{$V_{S}$} & $L$ & 0.490 \\
\hline & & $H^{2}$ & 0.921 \\
\hline \multirow{4}{*}{ Zone 4} & \multirow{2}{*}{$V_{C}$} & $L$ & 0.390 \\
\hline & & $H$ & 0.199 \\
\hline & \multirow[b]{2}{*}{$V_{S}$} & $L$ & 0.412 \\
\hline & & $H^{2}$ & 0.934 \\
\hline
\end{tabular}

Table 4. Multiple correlation analysis between the independent variable and $V_{C}$

\begin{tabular}{llll}
\hline Seismic Zone & Correlation Coefficient & Significance & Correlation Degree \\
\hline Zone 1 & 0.997 & 0.000 & Very Strong \\
Zone 2 & 0.997 & 0.000 & Very Strong \\
Zone 3 & 0.999 & 0.000 & Very Strong \\
Zone 4 & 0.998 & 0.000 & Very Strong \\
\hline
\end{tabular}

Table 5. Multiple correlation analysis between the independent variable and $V_{S}$

\begin{tabular}{llll}
\hline Seismic Zone & Correlation Coefficient & Significance & Correlation Degree \\
\hline Zone 1 & 0.997 & 0.000 & Very Strong \\
Zone 2 & 0.993 & 0.000 & Very Strong \\
Zone 3 & 0.991 & 0.000 & Very Strong \\
Zone 4 & 0.993 & 0.000 & Very Strong \\
\hline
\end{tabular}

Table 6. Correlation between seismic zone and abutment volumes ( $V_{C}$ and $V_{S}$ )

\begin{tabular}{lllll}
\hline Dependent Variable & Constant Variable & Correlation Coefficient & Significance & Correlation Degree \\
\hline$V_{C}$ & $L$ and $H$ & 0.880 & 0.000 & Very Strong \\
$V_{S}$ & $L$ and $H^{2}$ & 0.767 & 0.000 & Strong \\
\hline
\end{tabular}




\subsection{Multiple Linear Regression Analysis}

The multiple linear regression analysis produced several models and the concrete volume $\left(V_{C}\right)$ estimation models for each seismic zone 1, 2, 3, and 4 are presented in Equations (2), (3), (4), and

(5) respectively.

$$
\begin{aligned}
& V_{C}=0.930 L+49.070 H-99.378 \\
& V_{C}=0.899 L+48.349 H-85.244 \\
& V_{C}=0.968 L+55.948 H-105.090 \\
& V_{C}=1.196 L+65.756 H-136.169
\end{aligned}
$$

The reinforcing steel weight $\left(V_{S}\right)$ estimation models for each seismic zone $1,2,3$, and 4 are presented in Equations (6), (7), (8), and (9) respectively.

$$
\begin{aligned}
& V_{S}=143.590 L+360.075 H^{2}+2278.824 \\
& V_{S}=173.194 L+411.826 H^{2}+629.441 \\
& V_{S}=244.026 L+618.470 H^{2}-4456.373 \\
& V_{S}=356.777 L+879.685 H^{2}-9039.681 \\
& 4.7 \text { The Goodness of Fit Test }
\end{aligned}
$$

\subsection{The Goodness of Fit Test}

The goodness of fit test was conducted to determine the regression model performance. It was, however, expected that the models are good as long as all linear regression assumptions were fulfilled. Meanwhile, the goodness of fit was tested by evaluating the $R^{2}$ value and the results displayed in Table 7 showed all the models have values greater than 0.98 . This means the models were adequately designed to be used to estimate abutment volumes.

\begin{tabular}{lll}
\multicolumn{2}{l}{ Table 7. $R^{2}$ test result } \\
\hline Seismic Zone & Dependent Variable & $R^{2}$-value \\
\hline \multirow{2}{*}{1} & $V_{C}$ & 0.993 \\
& $V_{S}$ & 0.995 \\
\hline \multirow{2}{*}{2} & $V_{C}$ & 0.992 \\
& $V_{S}$ & 0.986 \\
\hline \multirow{2}{*}{3} & $V_{C}$ & 0.997 \\
& $V_{S}$ & 0.983 \\
\hline \multirow{2}{*}{4} & $V_{C}$ & 0.996 \\
& $V_{S}$ & 0.986 \\
\hline
\end{tabular}

\section{CONCLUSION}

This study proposed 4 concrete volume and 4 reinforcing steel weight estimation models and the statistical analysis results showed a very strong correlation between bridge span and abutment height towards the abutment volume. Meanwhile, the regression models were developed with all linear regression assumptions and the goodness of fit test for all the models had $R^{2}$ which is more than 0.98 and this means the models were adequately designed to be used to estimate abutment volumes. Moreover, the application of volumes estimated from these models and material unit price determined by the user made it possible to provide the initial cost estimate quickly and with flexibility.

The research showed a strong correlation between seismic zone and abutment volume but it was found to be non-linear while the type of data for the seismic zone was discovered to be ordinal or categorical and this has a very limited value. It was, however, recommended that seismic ground acceleration should be used as an independent variable to represent several bridge project locations to obtain wider, precise, and flexible data considering the fact that they are usually numerical data.

\section{DISCLAIMER}

The authors declare no conflict of interest.

\section{ACKNOWLEDGMENTS}

This study was supported by the Department of Civil and Environmental Engineering, Universitas Gadjah Mada, Yogyakarta, Indonesia.

\section{REFERENCES}

Alhusni, M. K., Triwiyono, A. \& Irawati, I. S., 2019. Material quantity estimation modelling of bridge sub-substructure using regression analysis. MATEC Web of Conferences, 258, p. 02008.

American Association of State Highway and Transportation Officials, 2012. AASHTO LRFD Bridge Design Specifications. 6th ed. Washington, D.C.: AASHTO.

Badan Standarisasi Nasional, 2004. Perencanaan struktur beton untuk jembatan (RSNI T-12-2004). Jakarta: BSN. 
Badan Standarisasi Nasional, 2016. Pembebanan untuk jembatan (SNI 1725:2016). Jakarta: BSN.

Badan Standarisasi Nasional, 2016. Perencanaan jembatan terhadap beban gempa (SNI 2833:2016). Jakarta: BSN.

Dimitriou, L., Marinelli, M. \& Fragkakis, N., 2018. Early Bill-of-Quantities Estimation of Concrete Road Bridges: An Artificial Intelligence-Based Application. Public Works Management \& Policy, 23(2), pp. 127-149.

Fragkakis, N., Lambropoulos, S. \& Tsiambaos, G., 2011. Parametric Model for Conceptual Cost Estimation of Concrete Bridge Foundations. Journal of Infrastructure Systems, 17(2), pp. 66-74.

Fragkakis, N., Marinelli, M. \& Lambropoulos, S., 2015. Preliminary cost estimate model for culverts. Procedia Engineering, 123, pp. 153-161.

Hollar, D. A. et al., 2013. Preliminary Engineering Cost Estimation Model for Bridge Projects. Journal of Construction Engineering and Management, 139(9), pp. 1259-1267.

Kim, B. S., 2011. The Approximate Cost Estimating Model for Railway Bridge Project in the Planning Phase Using CBR Method. KSCE Journal of Civil Engineering, 15(7), pp. 1149-1159.

Kim, G.-H., Shin, J.-M., Kim, S. \& Shin, Y., 2013. Comparison of School Building Construction Costs Estimation Methods Using Regression Analysis, Neural Network, and Support Vector
Machine. Journal of Building Construction and Planning Research, 1, pp. 1-7.

Mahamid, I., 2011. Early Cost Estimating for Road Construction Projects Using Multiple Regression Techniques. Construction Economics and Building, 11(4), pp. 87-101.

Oh, C. D., Park, C. \& Kim, K. J., 2013. An Approximate Cost Estimation Model based on Standard Quantities of Steel Box Girder Bridge Substructure. KSCE Journal of Civil Engineering, 17(5), pp. 877-885.

PT. Basis Pancakarya, 2019. karet-bantalanjembatan. [Online] Available at:

http://www.basisrubber.com/id/karet-bantalanjembatan.html [Accessed October 2019].

PT. Wijaya Karya (WIKA BETON), 2019. product. [Online] Available at: https://www.wikabeton.co.id/download-brosur/product [Accessed October 2019].

Sugiyono, 2019. Statistika untuk Penelitian. Bandung: CV. ALFABETA.

Swei, O., Gregory, J. \& Kirchain, R., 2017. Construction cost estimation: A parametric approach for better estimates of expected cost and variation. Transportation Research Part B, 101, pp. 295-305.

Williams, M. N., Grajales, C. A. G. \& Kurkiewicz, D., 2013. Assumptions of Multiple Regression: Correcting Two Misconceptions. Practical Assessment, Research, and Evaluation (PARE), 18, p. Article 11. 
[This page is intentionally left blank] 